\title{
THE IMPACT OF DIGITAL SOCIAL LEGITIMIZATION ON WEBSITE VISITS AND WEB SALES
}

\author{
Richard Heiens \\ University of South Carolina Beaufort \\ richardh@uscb.edu \\ Ravi Narayanaswamy \\ University of South Carolina Aiken \\ ravin@usca.edu
}

\begin{abstract}
The present manuscript examines the role of digital social influence, as attained through Facebook, Instagram, Pinterest, Twitter, and YouTube, in attracting customers and achieving sales performance. The theoretical mechanism that serves as the basis for the study is social legitimacy theory. Specifically, the influence exerted by social media and the resulting social legitimization of the marketer is expected to drive both website visits and, ultimately, sales for the USA's largest e-commerce retailers. The findings demonstrate that all five indicators of social media influence converge into a single variable with significant loadings. This provides support for the multidimensional nature of the hypothesized digital social legitimization construct. However, the analysis of the structural equation model indicates that there is not a direct link between digital social legitimization and Web sales performance. Nevertheless, digital social legitimization does in fact positively impact website visits. In turn, these visits are associated with higher e-commerce sales. Thus, marketers are advised to use social media to help legitimize the e-commerce brand and drive website traffic.
\end{abstract}

Keywords: e-commerce, social influence, digital social legitimacy, Web sales, consumer attraction.

\section{INTRODUCTION}

The master self-publicist, P.T. Barnum, once famously said, "I don't care what the newspapers say about me as long as they spell my name right". In Barnum's day, newspapers exerted a great deal of social influence. In his analysis on 19th century American society, Alexis de Tocqueville recognized newspapers for their socializing role. He viewed newspapers as the heart of society because they "express the opinions of the people, educate citizens, and gather together a citizenry otherwise in danger of dissolving into atomistic individuals" [1]. This is the process described by social legitimacy theory. Legitimacy can be thought of as the "collective perception or assumption that the actions of an entity are desirable, proper, or appropriate" [2]. Moving forward to the present day, the media landscape has been dramatically transformed. Traditional media are struggling to stay relevant as their authority is being replaced by influencers and regular people. In particular, social media has 
gained prominence as it enables consumers to instantly share their opinions and purchase decisions with their friends, family, and acquaintances, a principal step in the process of social legitimization.

Social legitimization is a micro-level phenomenon that occurs all the time as individuals make sense of their world [3]. In this ongoing process, social media play a dominant role [4]. In comparison, traditional advertising messages are constrained by their obvious persuasive intent. In fact, it has been suggested that consumers consider the information they obtain from social media to be far more trustworthy than marketing messages received through traditional channels [5]. Therefore, in contrast to traditional media, social networking sites represent a more efficient and effective channel of communication and promotion [6]. Accordingly, firms are increasingly seeking to capitalize on these online social networks to compensate for the decreasing effectiveness of traditional influence, such as mass media advertising [7]. This is a wise decision, as research reveals that consumers spend more time engaging in a combination of social networks than any other online activity [8]. As a result, the consumer decision process has become an increasingly digital experience [9]. Moreover, there is considerable cross-platform usage, as social media users rarely limit themselves to a single site [10].

It has been widely recognized in the field of advertising that there are often synergies to be gained from cross-platform marketing communications. One explanation is that "when consumers are exposed to multiple media in a campaign, they might perceive these media as independent sources of information and therefore more credible and persuasive than messages from a single source" [11]. Social media, in particular, offer an opportunity to utilize multiple platforms. Unfortunately, the nature of the relationship between digital social influence and marketing outcomes has not always been clear in the past. For instance, it has been noted that e-commerce retailers have been largely unable to quantify the return on investment in social media. One industry study reported that $59 \%$ of retailers believe that the returns from social media are unclear [12]. This may be due to the use of a disparate range of performance measures because the distinct nature of social media prohibits the simple transfer of metrics from traditional media [13]. For example, [14] proposed more than 50 metrics for specifically evaluating the effectiveness of social media, especially consumer outcome metrics such as brand awareness, brand engagement, and brand buzz. However, proponents of firm performance measurement suggest using financial indicators to evaluate the impact of social media investments [15]. Unfortunately, in the absence of precise sales data, most academic research has tended to focus on proxy variables, including conversion rates, purchase intentions, or even stock prices [16]; [17]; [18]. Nevertheless, without analyzing actual sales results, any examination of the effectiveness of a firm's social media marketing efforts is bound to be inconclusive. Therefore, is there actually a direct link between social media marketing and Web sales?

In the present study, we seek to answer this research question by analyzing the influence of social media on website traffic and Web sales data for the USA's top 500 e-commerce companies as ranked by annual Web sales. Considering the complementarity between the various social media platforms, we focus on five of the most prominent social media sites, including Facebook, Instagram, Pinterest, Twitter, and YouTube. Specifically, we introduce and test a model on the relationship between digital social influence achieved through these five social media platforms and two important performance measures, the number of website visits and Web sales. We 
begin by examining the influence of social media communications through the lens of social legitimacy theory. We go on to construct and empirically test a theoretical model on the relationship between digital social influence, website traffic, and Web sales. We conclude with a discussion regarding the managerial implications of our findings.

\section{SOCIAL LEGITIMACY THEORY}

As articulated by [2], "legitimacy is a generalized perception or assumption that the actions of an entity are desirable, proper, or appropriate within some socially constructed system of norms, values, beliefs, and definitions" (p. 574). The concept of social legitimacy was initially developed by researchers in the field of organizational behavior as a theoretical apparatus to address the dynamics which "constrain, construct and empower organizational actors" [2]. Thus, the origin of the concept of social legitimacy can be found within the realm of institutional theory. However, within the past decade, a handful of researchers have applied the concept of social legitimacy with the purpose of addressing why consumers perceive certain brands or consumption practices as legitimate but not others [19]; [20]; [21]. Social legitimacy is a broad construct, and different researchers have found various categories of legitimacy through which individuals evaluate companies and consumption practices. While the generalized definition of social legitimacy applies to them all, "each type of legitimacy rests on a somewhat different behavioral dynamic" [2].

It has been suggested that social legitimacy occurs on three levels: regulative, normative, and cultural-cognitive [22]. Regulative legitimacy refers to the degree to which a practice conforms to the rules and regulations set forth by a superseding organization, such as the government. Irrespective of legal status, normative legitimacy can be thought of as the degree to which a particular practice is perceived to be congruent with fundamental norms and values. Finally, cognitive legitimacy can be defined as the degree to which the practice can be categorized and understood according to existing cognitive schemas and cultural frameworks [2]. As reasoned by [21], cultural-cognitive legitimacy "occurs when consumers routinely inscribe frames on a brand with little reflective or critical thought" (p. 643). In other words, practices or products imbued with cultural-cognitive legitimacy are so overwhelmingly accepted as integral components of the social fabric that they may even serve as standards or archetypes in the minds of consumers. As a multilevel discourse-based construct, a wide range of media, communications methods, and authorities can be used as bases for these social legitimacy judgments [23].

In a consumer context, we would expect consumers to judge a product or consumption practice as legitimate or illegitimate based on whether the product is assigned cultural-cognitive legitimacy within the consumer's social group [24]. Cultural-cognitive legitimacy can be obtained through either explicit or implicit mechanisms. As described by [19], "legitimation can occur through explicit mechanisms such as consumer reward or punishment" (p. 491). In particular, if the product lives up to consumer expectations, it will likely be acknowledged as legitimate. In addition, and more commonly, social legitimacy may also be obtained through implicit mechanisms. For example, if a brand is seen as an established artifact of daily life, it will quickly attain cultural-cognitive legitimacy [19]. Considering the indispensable nature of mobile and online technologies to consumers' everyday lives, as well as the personal influence disseminated through this technology, social media 
serve as an ideal platform to elevate a brand's status and social legitimacy. In turn, this process helps to affirm one's social identity and bolsters one's sense of self-worth, which can help determine and reinforce consumer behavior [24].

\section{THE DIGITAL SOCIAL LEGITIMIZATION CONSTRUCT}

From the marketer's perspective, the use of digital media means that a larger customer base may become accessible, while the marginal cost of reaching these customers may be negligible [25]. As noted, social media can help facilitate discussions or comments regarding a brand or retailer, providing a useful tool for marketers to facilitate and encourage relevant user-generated content. It has been recognized that "legitimacy is shaped in social media platforms through the perceptions, judgments, and actions of individual contributors" [23]. These individual contributors give the company and its brand cognitive legitimacy by making it part of the reality of the community [19]. In fact, [13] acknowledges the social and cultural value of the interactions, which subsume the process of legitimization, as among the dominant motives that underly why consumers engage in social media.

A detailed review of social media research [26] identifies a wide range of marketing objectives supported by the various social media platforms available to marketers. These include awareness, engagement, referrals, and advocacy activities, which can all contribute to the process of social legitimization. Moreover, different platforms offer different outcomes. As such, one must consider a combination of social media when evaluating the totality of digital social influence. In the present study, we designate the construct of Digital Social Legitimization as being comprised of individual measures from five of today's most important social media platforms, including Facebook, Instagram, Pinterest, Twitter, and YouTube. The selection was based on reports that identify these five sites as the most popular social media platforms from which consumers shop online [27].

The largest social network is Facebook, which is viewed as a particularly efficient platform for social endorsement and opinion leadership [28]. As the most well-known social network, Facebook is an effective method for building trust and enhancing cognitive and cultural legitimacy. Launched in 2010 and purchased by Facebook in 2012, Instagram is a photo/visual-based social media platform. In recent years, Instagram has enjoyed a rapid rise in popularity. This is large because Instagram is optimized for self-presentation, which facilitates information sharing and social interaction [29]. Recent findings by [30] suggest that Instagram is especially effective in driving purchase intentions when product recommendations come from members of a user's social community.

Pinterest is another social media site that has been attracting the attention of advertisers in recent years. The primary focus of Pinterest is on discovering, archiving, and sharing visual images, allowing users to share their interests or lifestyles with like-minded others. In particular, many Pinterest users facilitate brand interactions by pinning or repinning branded images, which can have a positive impact on consumer purchases [31]. Twitter is a popular online social network in which users publicly communicate short messages to followers. Research shows that popularity alone, based on the number of followers, is an excellent predictor of Twitter's social influence [32]. Finally, YouTube is an attractive platform for creating and posting video content that can be shared almost instantaneously with a worldwide audience. YouTube users can subscribe to channels, comment on or choose favorite videos, and 
even post responses to other channels, making it an ideal platform for enabling social interactions and disseminating digital social influence.

\section{HYPOTHESIZED MODEL}

As mentioned previously, we began by hypothesizing the existence of a latent construct known as Digital Social Legitimization, which is inferred from social media metrics. The specific metrics used to represent the underlying construct of Digital Social Legitimization include consumer engagement criteria for each of the five social media sites included in the construct. In the case of Facebook, the variable used to represent Digital Social Legitimization includes the number of likes achieved by a marketer's Facebook page. For Twitter, Instagram, and Pinterest, the variable for each platform is the number of followers a marketer has accumulated. Finally, the variable used for YouTube includes the number of views achieved by a marketer. In addition, two observed outcome variables, actual Web Sales and Number of Visits to the marketer's website, were included in the hypothesized model shown in Figure 1.

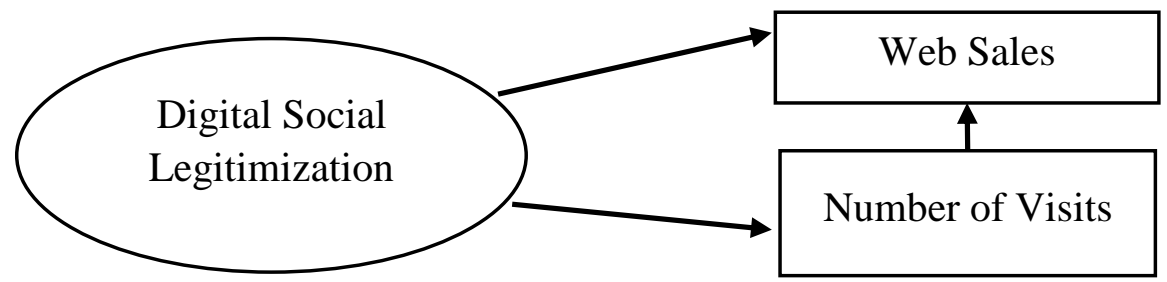

Figure 1. Hypothesized Model

As seen in Figure 1, it is expected that the latent construct known as Digital Social Legitimization, as derived from the five social media variables previously mentioned, will have a direct impact on Web Sales. Previous research has already provided some degree of validation for the contention that online social influence has a positive effect on sales. For example, a recent study by [33] discovered that Facebook "likes" and Twitter "tweets" can significantly boost sales for products featured in special promotional deals. Extending these findings to the broader construct of Digital Social Legitimization, we can also expect a positive impact on overall Web Sales.

[34] recently demonstrated that when a particular website is perceived to be heavily endorsed by the members of one's social group, the consumer's intention to use that site increases. This is true no matter how close and important the group of people are to the individual. In other words, not only do close friends influence consumer behavior, but members of the broader social network that may even be largely unknown to the user can also exert social influence. Therefore, it can be expected that Digital Social Legitimization, as derived from the five social media variables previously mentioned, will have a direct impact on the Number of Visits.

A study of e-commerce retailers [35] reports that visit duration and the number of pages viewed are both related to sales. As the website is the main point of contact that e-commerce retailers have with online shoppers, maximizing the number of visitors to a given website each month is also likely to be an important determinant of online retail sales. Therefore, not only do we expect Digital Social Legitimization to 
attract consumers to the website, but we also expect that the number of consumers visiting the site will have a direct and significant positive impact on Web Sales.

\section{DATA AND ANALYSIS}

The data used to test the hypothesized model were gathered from Internet Retailer's Top 500 Database for the year 2018. [36] This database contains profiles and data on the USA's top 500 e-commerce companies ranked by annual Web sales. The database provides a total of 231 metrics for each e-commerce firm, which includes financial, operational, customer service, marketing, corporate information, executive profiles, website performance, and vendor information. To compile the database, the data collection process was conducted in a systematic manner. The internal research staff from Internet Retailer contacted the online retailers directly to obtain the data. If the online retailers did not respond, Internet Retailer factored in its historical knowledge about each retailer and its business, comparisons to other retailers in the same category, expert opinions from technology vendors and market analysts, and its general knowledge of the industry, which was provided by information partners such as comScore Inc., Experian Marketing Services, and ForSee, among others. Finally, online retailers were given several opportunities to respond to estimates so that they could be revised if necessary. Because of the systematic procedures employed in the data collection process, several previous academic research studies have been based on earlier versions of the database (e.g., [16]; [37]).

The hypothesized model was tested via a hybrid Structural Equation Model (SEM) with one latent variable and two observed variables using IBM SPSS and AMOS version 26. While SEM is a robust estimation technique, it requires a thorough understanding of the assumptions and conditions underlying its use, without which the application can be seriously flawed or invalid. Accordingly, necessary checkpoints were initiated using the procedure outlined by [38] and [39]. The first checkpoint was to scan the data for missing values. Because missing values can often inflate and distort results [40], only those e-commerce retailers that reported data for each of the five indicators of Digital Social Legitimization during the year 2018 were included in the study. This process resulted in a sample size of 417 qualified e-commerce retailers out of the original 500 in the database. Also, because abnormal data can suppress the model fit and cause spurious estimation, the second checkpoint was to identify multivariate outliers. The standard method for multivariate outlier detection is the robust estimation of the parameters using the "Mahalanobis distance", which are then compared against critical values on the chi-square distribution [41]. A common recommendation is to delete data points with probability values less than .001 [39]. At the end of this process, a total of 400 e-commerce retailers remained in the sample. The final checkpoint involved an analysis of sample size. With one latent variable, two observed variables, a p-value of 0.05 , and a desired statistical power of 0.8 , the sample of 400 proved to be more than sufficient for structuring the model [42].

\section{FINDINGS}

Descriptive statistics for each of the variables included in the study are provided in Table 1. To ensure consistency and avoid any spurious estimation, the variables were recorded using mean centering. A confirmatory factor analysis was also conducted to examine the dimensionality of the indicators for the latent social legitimization variable referred to as Digital Social Legitimization. The results 
summarized in Table 2 show that all five of the indicators converge into a single variable with significant loadings. This provides support for the multidimensional nature of our hypothesized Digital Social Legitimization construct. Accordingly, in order to capture the full extent of Digital Social Legitimization, it is important to take a holistic approach rather than focusing on measures related to any single social media site. In other words, in the e-commerce context, social legitimization can best be facilitated through a combination of the five most prominent social media platforms.

Table 1. Descriptive Statistics for Research Variables

\begin{tabular}{cllll}
\hline & \multicolumn{1}{c}{ Minimum } & \multicolumn{1}{c}{ Maximum } & \multicolumn{1}{c}{ Mean } & \multicolumn{1}{c}{ Std. Deviation } \\
\hline Number of Visits & 35087.00 & 2468780128.00 & 18504294.07 & 133807512.84 \\
Web Sales & 7228651.33 & 14991666666.67 & 114428176.05 & 784303289.01 \\
Facebook & 763.00 & 35891924.00 & 2609200.70 & 5625763.41 \\
Instagram & 56.00 & 84436730.00 & 1448613.63 & 6129668.78 \\
Pinterest & 42.00 & 37190705.00 & 205317.25 & 1902219.65 \\
Twitter & 182.00 & 11218224.00 & 321157.34 & 1101537.96 \\
YouTube & 1435.00 & 2151691900.00 & 32304779.00 & 120749264.57 \\
\hline
\end{tabular}

$\mathrm{N}=400$, number of visits - number of consumers visiting the site; Number of sales dollar value; Facebook - number of likes; Instagram, Pinterest, Twitter - number of followers; YouTube - number of views

The estimation of the SEM model was performed using the maximum likelihood procedure. The results are shown in Figure 2. As predicted, it is a recursive model where all causal effects are uni-directional. However, a good-fitting measurement model is required before interpreting the causal paths of the structural model. The overall model fit, along with the acceptance criteria defined by [38] and [39], is summarized in Table 3. The model fit indices shown in Table 3 reveal that the model is a "good fit" as it meets or exceeds the acceptance criteria for both absolute and relative, or incremental, fit indices.

Table 2. Confirmatory Factor Analysis Results

\begin{tabular}{clcl}
\hline Component & 1 & 2 & 3 \\
\hline Web Sales & & .923 & \\
Number of Visits & & & .773 \\
Facebook & .729 & & \\
Instagram & .875 & & \\
Pinterest & .832 & & \\
Twitter & .732 & & \\
YouTube & .611 & & \\
\hline
\end{tabular}

Although there is some degree of controversy regarding the use of model fit indices in SEM, absolute fit indices such as the Root Mean Square Error of Approximation (RMSEA) and the Standardized Root Mean Square (SRMR) have gained prominence in recent years. The RMSEA for this model was .069, which implies a "good fit" and provides support for the hypothesized model. Similarly, well-fitting models typically obtain values less than 0.08 for the SRMR [43]. As shown in Table 3, the SRMR was .032, implying a parsimonious fit and also lending support to the structured model. In addition, relative or incremental fit indices 
include the Chi-sq/df ratio, the Goodness-of-Fit Index (GFI), the Adjusted Goodness-of-Fit Index (AGFI), the Comparative Fit Index (CFI), the Normed Fit Index (NFI), and the Tucker Lewis Index (TLI). The structured model meets or exceeds the threshold values for each of these, once again indicating "good fit". The TLI, in particular, with a reported value of .956, implies that the variables used in the model as indicators of Digital Social Legitimization are both consistent and parsimonious. Therefore, the next step is to examine the direct, total, and indirect effects.

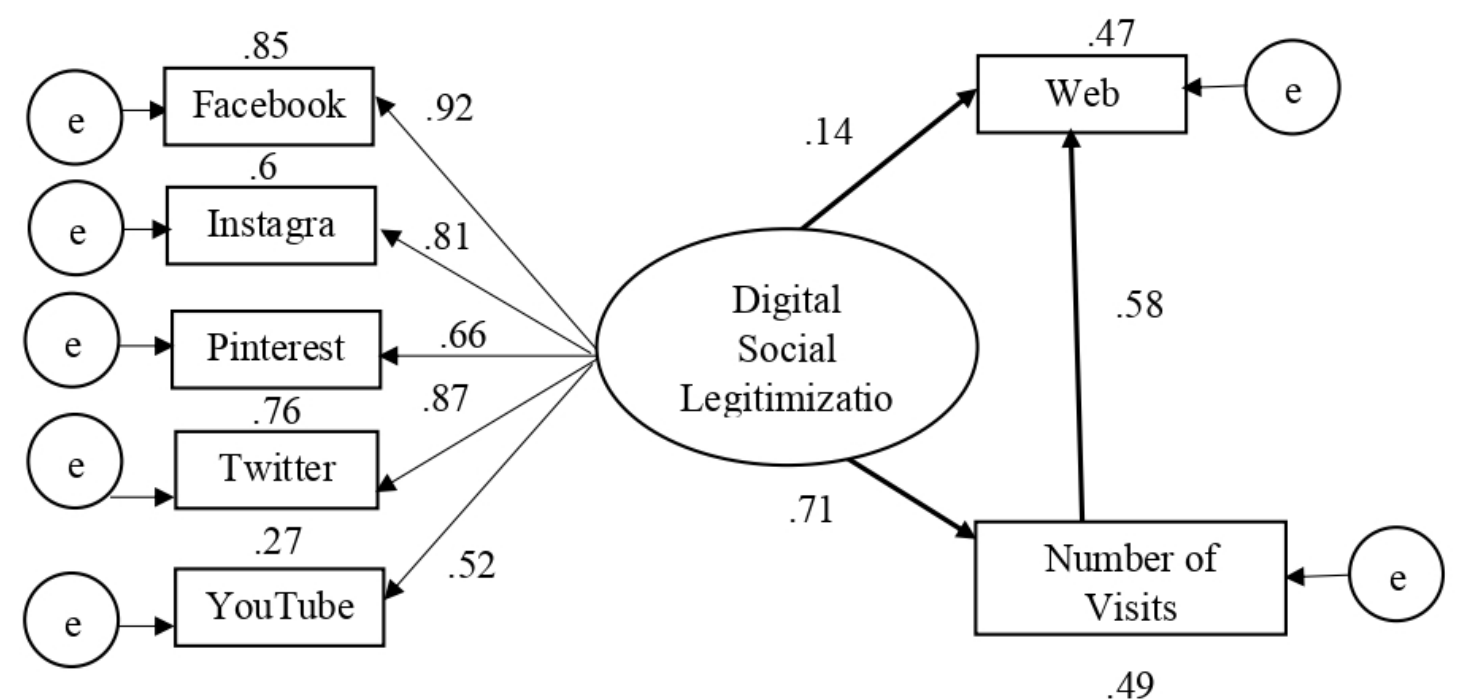

*indicates squared multiple correlations(R2)

Figure 2. Results of the Structural Equation Model

Table 3. Model Fit Summary

\begin{tabular}{|c|c|c|c|}
\hline Measure & Statistic & $\begin{array}{l}\text { Acceptance } \\
\text { Criteria }\end{array}$ & Indication \\
\hline Chi-sq/df & 4.56 & $2.0-5.0$ & Model fits the sample data \\
\hline GFI & .967 & $>=.95$ & $\begin{array}{l}\text { The proportion of variance accounted for by } \\
\text { the estimated population covariance was } \\
\text { significant }\end{array}$ \\
\hline AGFI & .920 & $>=.90$ & Model fits the sample data \\
\hline NFI & .971 & $>=.95$ & $\begin{array}{l}\text { The model of interest improves the fit by } \\
97.1 \text { percent relative to the null model }\end{array}$ \\
\hline TLI & .956 & $>=.95$ & Sensitivity to sample size \\
\hline CFI & .977 & $>=.95$ & The fit of the target model is significant \\
\hline SRMR & .032 & $<.08$ & $\begin{array}{l}\text { The square-root of the difference between } \\
\text { the residuals of the sample covariance } \\
\text { matrix and the hypothesized model }\end{array}$ \\
\hline RMSEA & .069 & .06 to .08 & A parsimony adjusted index shows good fit \\
\hline
\end{tabular}

As shown in both Figure 3 and Table 4, all of the relationships between the variables are positive, although with varying degrees of magnitude. For example, the standardized coefficients reveal a stronger connection between Digital Social Legitimization and the Number of Visits, in comparison to the relationship between Digital Social Legitimization and Web Sales. The standardized direct (unmediated) 
effect of Digital Social Legitimization on Web Sales is only .14. Therefore, the contention that Digital Social Legitimization directly impacts Web Sales is not supported $(\mathrm{p}>.10)$.

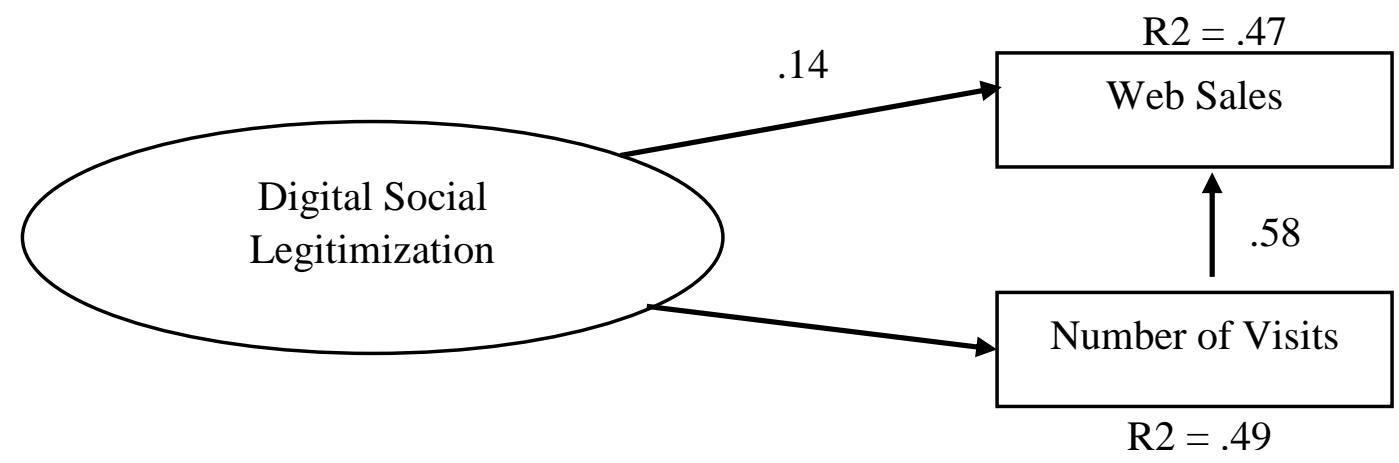

Figure 3. Effects Model

In contrast, the findings indicate that Digital Social Legitimization does help attract consumers to the website. Therefore, the notion that Digital Social Legitimization directly impacts the Number of Visits is supported. Inasmuch, Digital Social Legitimization is a good predictor (standardized coefficient $=.70, \mathrm{p}<.001$ ) of the number of customers visiting the website. This is important because, as hypothesized by the model, the standardized direct (unmediated) effect of the Number of Visits on Web Sales is significant (standardized coefficient $=.58, \mathrm{p}<.001$ ).

Because of the positive and significant relationship between the Number of Visits and Web Sales, as shown in Table 4, the indirect (mediated) effect of Digital Social Legitimization on Web Sales is .406. More importantly, the standardized total (direct and indirect) effect of Digital Social Legitimization on Web Sales is .546. That is, Digital Social Legitimization does benefit the e-commerce retailers in two ways; through both attracting consumers to the website and, and least indirectly, through improving Web sales. In summary, it is viable to conclude that Digital Social Legitimization is an important factor to be considered for improving performance in the e-commerce environment.

Table 4. Direct, Indirect, and Total Effects

\begin{tabular}{llcr}
\hline Model & & Standardized Beta & Standard Error \\
\hline Direct Effect & & .703 & .094 \\
Social Legitimization & Number of Visits & .140 & .060 \\
Social Legitimization & Web Sales & .577 & .039 \\
Number of Visits & Web Sales & & \\
Indirect Effect & & .406 & \\
Social Legitimization & Web Sales & & \\
Total Effect & & .546 & \\
Social Legitimization & Web Sales & .577 & \\
Number of Visits & & & \\
\hline
\end{tabular}




\section{DISCUSSION AND FUTURE RESEARCH SUGGESTIONS}

One important contribution of the current study is related to the development of the Digital Social Legitimization construct. Social legitimacy represents the perceived authenticity and acceptability of the firm, its products, and its messages. As described by [3], perceptions regarding social legitimacy affect consumers' everyday lives, as individuals look for social cues to help make sense of their world. As such, one can use the concept of social legitimacy to understand the impact of socially mediated communications, especially those that are conveyed through social media. Social media allow for the widespread distribution of the perceptions, judgments, and actions of the social group. In today's media landscape, social media may even be the primary tool for the social legitimization of the brand. Therefore, for this study, we identified five social media indicators that are likely to impact social legitimacy perceptions. As described previously, these include the number of likes for Facebook, the number of followers for Twitter, Instagram, and Pinterest, and the number of views for YouTube. Factor analysis results reinforce the validity of the Digital Social Legitimization construct, as all five indicators do in fact converge into a single variable with significant loadings.

Social motivation can be a powerful force that drives consumer behavior, and one major societal change taking place today is that, in contrast to the traditional influence of mass media, individuals are increasingly taking cues from one another [44]. For example, [39] demonstrate that intention to use a given e-commerce site is strongly influenced by whether or not individuals perceive the behavior to be endorsed by their friends and members of their social network. Our findings reinforce this notion, as we show that Digital Social Legitimization does indeed help attract consumers to the website. Specifically, the proposed link between Digital Social Legitimization and website visits is supported. Consistent with [11], our findings also suggest that marketing campaigns utilizing multiple social media platforms may be particularly effective as these messages reinforce one another and provide the social proof necessary for the legitimization of the e-commerce brand. This appears to help drive website traffic, which in turn creates positive sales outcomes. Moreover, it is important for marketers to encourage website visits, as research indicates that these visits can improve offline sales as well [45].

With regard to the initial research question regarding the link between social media marketing and Web sales, one important finding from the current study is that the measures of social media marketing outcomes utilized in the study are not directly linked to the Web Sales variable. Nevertheless, we should point out that the current study focused solely on the 500 largest e-commerce retailers in the U.S. market. One way to interpret this outcome is that top-ranked online retailers are not necessarily marketers with the most aggressive or effective social influence tools. It is possible that smaller retailers rely more heavily on social media networks. Because they are inexpensive and don't require high-level technological competencies to employ, social media open up a wide range of opportunities for small businesses [46]. As such, many small businesses have been quick to take advantage of social media to expand their reach and realize their business goals [47]. Thus, it may not be surprising that the measurable outcomes of social media users are not necessarily correlated with sales. Analyzing data from smaller retailers could possibly reveal different findings.

Another way to consider this outcome is that it is consistent with studies suggesting that digital social influence effects may vary over time. According to [7], 
although social influence plays a significant role in the adoption process for new innovations, its effectiveness tends to decrease from the product introduction onward. [48] also conclude that as familiarity with a product becomes more widespread, information obtained through social contacts becomes less important. Therefore, the large e-commerce retailers included in the study may no longer be as dependent on social media for their Web sales as they once were. However, in order to fully understand the dynamic effects of social media influence over time, future research may need to examine the hypothesized relationships at a variety of different stages throughout the product life cycle.

In addition, referring back to Figure 2, the findings related to each social media platform bear some discussion. Considering the comprehensive nature of the social legitimization process, it is important for a marketer to develop a cohesive social media strategy that incorporates several different platforms, each with its own unique strengths. However, of the five prominent platforms included in the operationalization of the hypothesized Digital Social Legitimization construct, our findings suggest that YouTube may contribute least to the process of social legitimization. One possible explanation may be related to the measures employed in the current study. Whereas the variable used for YouTube only included the number of views achieved by a marketer, one of the primary characteristics of YouTube is that it can also host usergenerated content. Specifically, YouTube enables users to participate in conversations around the video ads posted on the platform by either posting their own comments or observing the comments on the video posted by other viewers. Although the specific nature of these activities may be difficult to deconstruct, [49] recently proposed a methodology for classifying YouTube comments into one of four categories: inquiry, laudation, debate, or flame. Similarly, as proposed by [50], other measures of engagement, such as the level of personal disclosure, message virality, and even stakeholder mood could be employed. If future research were to incorporate either these or similar schemes for measuring engagement, it is possible that YouTube might exhibit a greater contribution to the Digital Social Legitimization construct.

Finally, an important avenue for future research would be to extend the proposed model to a different context. While the current study focused solely on U.S. based e-commerce retailers, it would be interesting to determine if similar findings would occur in either the offline environment or in different geographic markets. It is possible that cultural differences across countries could impact the nature and magnitude of the digital social legitimization process described in the current study.

\section{REFERENCES}

[1] Bunting, T.D., A Bible, an ax, and a tablet: Tocqueville's newspapers and everyday political discourse. Perspectives on Political Science, 46(4), p. 257-269, 2017.

[2] Suchman, M., Managing legitimacy: Strategic and institutional approaches. Academy of Management Review, 20(3), p. 571-611, 1995.

[3] Coskuner-Balli, G., Market practices of legitimization: Insights from consumer culture theory. Marketing Theory, 13(2), p. 193-211, 2013.

[4] Alves, H., Fernandes, C., and Raposo, M., Social media marketing: A literature review and implications. Psychology and Marketing, 33(12), p. 1029-1038, 2016.

[5] Foux, G., Consumer-generated media: Get your customers involved. Brand Strategy, 8, p. 38-39, 2006. 
[6] Antoniadis, I., and Charmantzi, A., Social network analysis and social capital in marketing: Theory and practical implementation. International Journal of Technology Marketing, 11(3), p. 344-359, 2016.

[7] Risselada, H., Verhoef, P. C., and Bijmolt, T. H. A., Dynamic effects of social influence and direct marketing on the adoption of high-technology products. Journal of Marketing, 78(2), p. 52-68, 2014.

[8] Biucky, S.T., Abdolvand, N., and Harandi, S.R., The effects of perceived risk on social commerce adoption based on the Tam model. International Journal of Electronic Commerce Studies, 8(2), p. 124-147, 2017.

[9] Belch, G., and Belch, M., The role of new and traditional media in the rapidly changing marketing communications environment. International Journal of Strategic Innovative Marketing, 1(3), pp. 130-136, 2014.

[10] Zafarani, R., and Liu, H., Users joining multiple sites: Friendship and popularity variations across sites. Information Fusion, 28, p. 83-89, 2016.

[11] Neijens, P. and Voorveld, H., Cross-platform advertising: Current practices and issues for the future. Journal of Advertising Research, 55(4), p. 362-367, 2015.

[12] Mulpuru, S., Harteveldt, H. H., and Roberge, D., Five retail e-commerce trends to watch in 2011. Forrester Research Report, (January 31), 2011.

[13] Peters, K., Chen, Y., Kaplan, A. M., Ognibeni, B., \& Pauwels, K., Social media metrics-A framework and guidelines for managing social media. Journal of Interactive Marketing, 27(44), p. 281-298, 2013.

[14] Hoffman, D. and Fodor, M., Can you measure the ROI of your social media marketing? MIT Sloan Management Review, 52(1), p. 41-49, 2010.

[15] Tiago M.T.P.M.B. and Verissimo, J.M.C., Digital Marketing and social media: Why bother? Business Horizons, 57, p. 703-708, 2014.

[16] Gudigantala, N., Bicen, P., and Eom, M., An examination of antecedents of conversion rates of e-commerce retailers. Management Research Review, 39(1), p. 82-114, 2016.

[17] Rajgopal, S., Venkatachalam, M. and Kotha, S., Managerial actions, stock returns, and earnings: The case of business-to-business Internet firms. Journal of Accounting Research, 40(2), p. 529-556, 2002.

[18] Van Slyke, C., Belanger, F., and Comunale, C. L., A behavioral beliefs model of trustworthiness in consumer oriented e-commerce. Journal of Electronic Commerce in Organizations, 7(2), p. 22-43, 2009.

[19]Humphreys, A., Semiotic structure and the legitimation of consumption practices: The case of casino gambling. Journal of Consumer Research, 37(October), p. 490-510, 2010.

[20] Humphreys, A. and Latour, K. A., Framing the game: Assessing the impact of cultural representations on consumer perceptions of legitimacy. Journal of Consumer Research, 40(4), p. 773-795, 2013.

[21] Kates, S. M., The legitimate brand. in Advances in Consumer Research, 32, eds. Geeta Menon and Akshay R. Rao, Duluth, MN: Association for Consumer Research, p. 643-643, 2005.

[22] Scott, W. R., Institutions and Organizations, Newbury Park, CA: Sage, 1995.

[23] Hakala, H., Niemi, L., and Kohtamäki, M., Online brand community practices and the construction of brand legitimacy. Marketing Theory, 17(4), p. 537-558, 2017.

[24] Tost, L., An integrative model of legitimacy judgments. Academy of Management Review, 36(4), p. 686-710, 2011. 
[25] Cattani, K., Gilland, W., Heese, H.S., and Swaminathan, J., Boiling frogs: Pricing strategies for a manufacturer adding a direct channel that competes with the traditional channel. Production and Operations Management, 15(1), p. 40-56, 2006.

[26] Misirlis, N., and Vlachopoulou, M., Social media metrics and analytics in marketing-S3M: A mapping literature review. International Journal of Information Management, 38(1), p. 270-276, 2018.

[27] Global Web Index, "The latest social media trends to know in 2019", retrieved on August 9, 2019, from https://www.globalwebindex.com/reports/social.

[28] Anspach, N. M., The new personal influence: How our Facebook friends influence the news we read. Political Communication, 34(4), p. 590-606, 2017.

[29] Kim, B. and Kim, Y., Facebook versus Instagram: How perceived gratifications and technological attributes are related to the change in social media usage. Social Science Journal, 56(2), p. 156-167, 2019.

[30] Talib, Y. Y. A., and Saat, R. M., Social proof in social media shopping: An experimental design research. in SHS Web of Conferences, Vol. 34, p. 02005, 2017.

[31] Youn, S. and Jin, S. V., Reconnecting with the past in social media: The moderating role of social influence in nostalgia marketing on Pinterest. Journal of Consumer Behaviour, 16(6), p. 565-576, 2017.

[32] Garcia, D., Mavrodiev, P., Casati, D., and Schweitzer, F., Understanding popularity, reputation, and social influence in the Twitter society. Policy \& Internet, 9(3), p. 343-364, 2017.

[33] Kim, N., and Kim, W., Do your social media lead you to make social deal purchases? Consumer-generated social referrals for sales via social commerce. International Journal of Information Management, 39, p. 38-48, 2018.

[34] Osatuyi, B., and Turel, O., Social motivation for the use of social technologies. Internet Research, 29(1), pp. 24-45, 2019.

[35] Panagiotelis, A., Smith, M. S., and Danaher, P. J., From Amazon to Apple: Modeling online retail sales, purchase incidence, and visit behavior. Journal of Business \& Economic Statistics, 32(1), p. 14-29, 2014.

[36] Internet Retailer, The year ahead: The trends and key developments retailers can expect to encounter in 2019. Digital E-commerce. retrieved July 6, 2019, from http://www.digitalcommerce360.com/IR, 2018.

[37] Ranganathan, C. and Grandon, E., An exploratory examination of factors affecting online sales. Journal of Computer Information Systems, 42(3), p. 87-93, 2002.

[38] Kline, R. B., Methodology in the social sciences. Principles and practice of structural equation modeling (4th ed.). New York, NY, US: Guilford Press, 2016.

[39] Tabachnick G. B. and Fidell, S. L., Using Mutlivariate Statistics, $7^{\text {th }}$ edition, Boston: Pearson Publishing, 2019.

[40] Allison, D.P., Missing data techniques for structural equation modeling. Journal of Abnormal Psychology, 112(4), p. 545-557, 2003.

[41] Mahalanobis, P. C., On the generalized distance in statistics. Proceedings of the National Institute of Sciences of India, 2(1), p. 49-55, 1936.

[42] Westland, J. C., Lower bounds on sample size in structural equation modeling. Electronic Commerce Research and Applications, 9(6), p. 476-487, 2010.

[43] Hu, L. T. and Bentler, P. M., Cutoff criteria for fit indexes in covariance structure analysis: Conventional criteria versus new alternatives. Structural Equation Modeling, 6(1), p. 1-55, 1999. 
[44] Vannoy, S. A. and Palvia, P., The social influence model of technology adoption. Communications of the ACM, 53(6), p. 149-153, 2010.

[45] Lobschat, L., Osinga, E. C. and Reinartz, W. J., What happens online stays online? Segment-specific online and offline effects of banner advertisements. Journal of Marketing Research, 54(6), p. 901-913, 2017.

[46] Cesaroni, F. M., and Consoli, D., The adoption and use of social media by micro and small enterprises. Proceedings of the European Conference on E-Learning, p. 65-72, 2015.

[47] Shilpa, B. and Janhavi, R., Mining for social media: Usage patterns of small businesses. Business Systems Research, 8(1), p. 43-50, 2017.

[48] Chen, Y., Wang, Q., and Xie, J., Online social interactions: A natural experiment on word of mouth versus observational learning. Journal of Marketing Research, 48(2), p. 238-54, 2011.

[49]Feng, Y., Chen, H., and He, L., Consumer responses to femvertising: A datamining case of Dove's "campaign for real beauty" on YouTube. Journal of Advertising, 48(3), p. 292-301, 2019.

[50] Bonsón, E., and Ratkai, M., A set of metrics to assess stakeholder engagement and social legitimacy on a corporate Facebook page. Online Information Review, 37(55), p. 787-803, 2013. 